Original Article

\title{
METHOD DEVELOPMENT AND VALIDATION OF EPROSARTAN MESYLATE AND ITS IMPURITIES USING REVERSE PHASE HIGH-PERFORMANCE LIQUID CHROMATOGRAPHY
}

\author{
O. S. S. CHANDANA ${ }^{1}$, D. SATHIS KUMAR ${ }^{2}$, R. RAVICHANDRA BABU ${ }^{1^{*}}$
}

${ }^{1}$ Department of Chemistry, Institute of Science, Gitam University, Visakhapatnam, Andhra Pradesh, India, ${ }^{2}$ Aditya Institute of Pharmaceutical Sciences and Research, Surampalem, Andhra Pradesh, India 533437

Email: rrcbabu7@yahoo.in

Received: 19 Jul 2016, Revised and Accepted: 20 Aug 2016

\section{ABSTRACT}

Objective: Our main objective is to develop an accurate and precise RP-HPLC method for the determination of Eprosartan Mesylate and its impurities.

Methods: A Develosil ODS UG-5; $(150 \times 4.6) \mathrm{mm} ; 5 \mu \mathrm{m}$ column was used for the Separation of drugs by a mobile phase consisting of Buffer and Acetonitrile mixture in the gradient proportion. The flow rate maintained was $0.8 \mathrm{ml} / \mathrm{min}$ and the wavelength used for detection was $235 \mathrm{~nm}$.

Results: The linearity was observed in the range of $0.025-50 \mu \mathrm{g} / \mathrm{ml}$ of spiked impurities in Eprosartan Mesylate, impurity 1 and impurity 2 with a correlation coefficient of $0.99927,0.99910$ and 0.99934 respectively. The mean percentage recoveries for LOQ, 50\%, 80\%, 100\%, $150 \%$ and $200 \%$ accuracy were found to be $101.5 \pm 1.51,107.0 \pm 1.7,104.6 \pm 0.4,102.8 \pm 0.36,101.7 \pm 0.26$ and $101.3 \pm 0.15$ respectively for impurities in Eprosartan Mesylate, impurity 1 and impurity 2. Linearity, accuracy, precision and robustness parameters for the suggested method were estimated for validation.

Conclusion: The developed method is uncomplicated, accurate, sensitive and precise for the determination of related substances in the Eprosartan Mesylate. The satisfying \% recoveries and low \% RSD Values confirmed the suitability of the developed method for the usual analysis of Eprosartan mesylate in pharmaceuticals.

Keywords: Eprasartan impurities, HPLC, Method Development, Validation, Forced degradation studies

(C) 2016 The Authors. Published by Innovare Academic Sciences Pvt Ltd. This is an open access article under the CC BY license (http://creativecommons.org/licenses/by/4.0/) DOI: http://dx.doi.org/10.22159/ijcpr.2016v8i4.15277

\section{INTRODUCTION}

Eprosartan Mesylate (EM) Antagonizes the effect of angiotensin II (vasoconstriction and aldosterone secretion) by blocking the angiotensin II receptor (AT 1 receptor) in vascular smooth muscle and the adrenal gland, producing decreased Blood Pressure. $\mathrm{C} 23 \mathrm{H} 24 \mathrm{~N} 2 \mathrm{O} 4 \mathrm{~S} \cdot \mathrm{CH} 4 \mathrm{O} 3 \mathrm{~S}$ and $520.62 \mathrm{~g} / \mathrm{Mol}$ are chemical formula and molecular weight of EM. The structural formula of EM is shown in fig. 1 (a). It is insoluble in water $(0.00866 \mathrm{mg} / \mathrm{ml})$ [1]. Impurity A is chemically known as alpha \{2-butyl-1\{\{4-(methoxy carbonyl) phenyl) methyl\}-1H-imidazol-5-yl\} methylene\}-2-thiophene propanoic acid ethyl ester. Impurity B is chemically known as 2Carbethoxy-3-(2-thienyl) sodium propionate [2-4].

The development and validation of an analytical method is to ensure a specific, accurate and precise method for a particular analyte. The principal objective for that is to enhance the conditions and parameters, which should be observed in the evolution and establishment. From the literature review, it was found that there are few methods for the estimation of EM, Impurity A and Impurity B. but many methods for individual analysis of the drugs are present [5-14]. Hence it is aimed to acquire novel methods for the estimation of EM, impurity A and Impurity B using available analytical technique HPLC. Granting to the literature survey, few analytical methods such as UV-Visible (Vis) spectrophotometry [5-8], RP-HPLC [9-12], HPTLC [13] methods were covered for the estimation of EM individually and LC-MS and LCNMR method is for degradation products of EM [14]. The aim of the suggested method is to develop a simple and accurate methods for the determination of EM and its impurities A and B using the RP-HPLC technique in tablets.

\section{MATERIALS AND METHODS}

\section{Chemicals and reagents}

EM, Impurities A and B obtained from Fortune Laboratories (India) were of analytical grade ( $99.9 \%$ pure). Commercial samples of EM tablets were procured from the local medical store and applied within their shelf-life period.

Acetonitrile and Water of HPLC grade and $\mathrm{KH}_{2} \mathrm{PO}_{4}$ were obtained from Rankem R. F. C. L. Limited, Haryana, SD Fine Chem. Limited, Mumbai and MARCK Specialities private limited, Mumbai respectively.

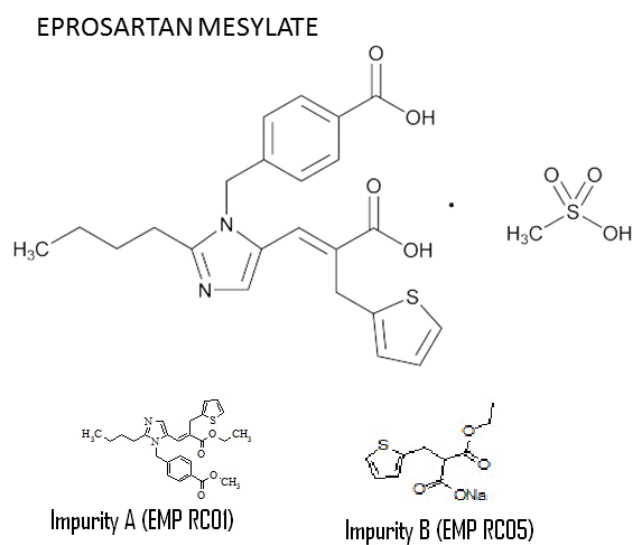

Fig. 1: Structure of eprosartan mesylate and its impurities
Chramatographic system
Quantitative HPLC was performed on PEAK chromatographic chemisorption version B.02.01 with Variable wavelength programmable UV detector VWD G1314A. Develosil ODS UG-5; (150 $\times 4.6 \mathrm{~mm}$; packed with $5 \mu \mathrm{m}$ particles) is utilized for the chromatographic separation. 


\section{Chromatographic conditions}

Manual injections $(20 \mu \mathrm{l})$ were applied. The column was kept at ambient temperature. The wavelength was set at $235 \mathrm{~nm}$ for detection. To produce a suitable RP-HPLC method for the determination of EM, different mobile phases buffer, water and acetonitrile were used in different compositions at different flow rates. Lastly, the mobile phase Buffer(mobile phase A) and acetonitrile (Mobile phase B) mixture in the gradient proportion at a flow rate of $0.8 \mathrm{ml} / \mathrm{min}$ gave peaks with good resolution for EM, impurity A and B. EM, impurity A and B got eluted at retention times 7.76, 14.03 and 18.66 min respectively with symmetric peaks. The mobile phase was degassed and then filtered through $0.25 \mu \mathrm{m}$ Microfiltration unit before it was pumped into the RP-HPLC system. By pumping the mobile phase through the column for at least $30 \mathrm{~min}$ before injecting the drug solution, equilibrium in the column was achieved. $21 \mathrm{~min}$ were the run time. Chromatogram showing the separated drugs is shown in fig. 2.

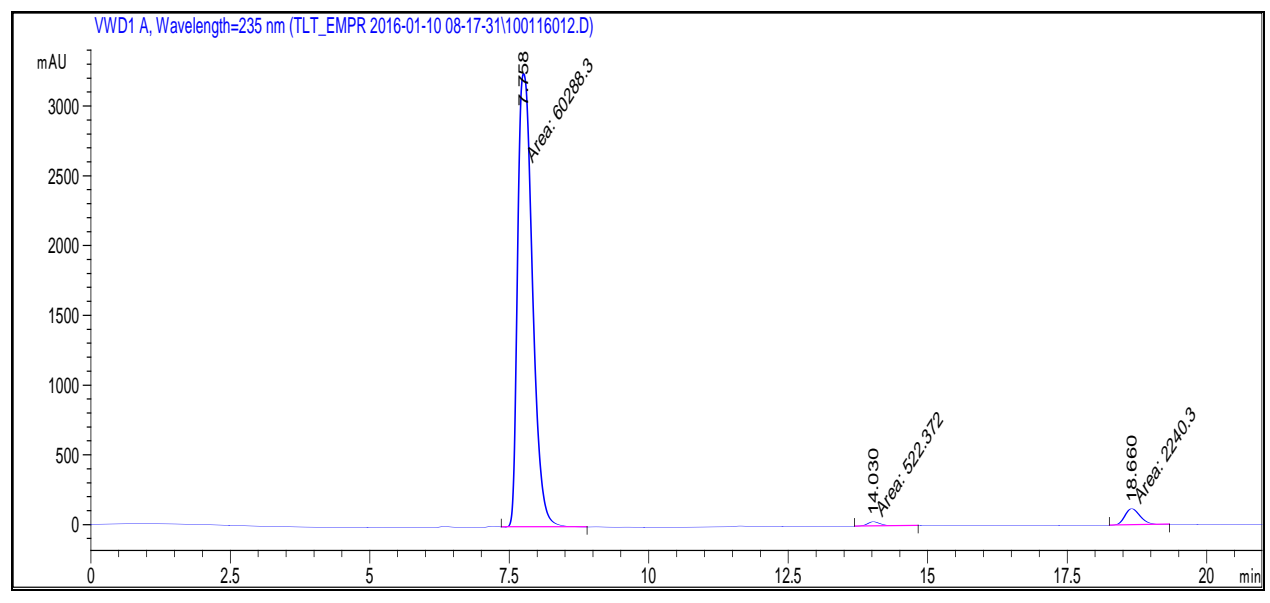

Fig. 2: Chromatogram of eprosartan mesylate and its impurity

\section{Mobile phase preparation}

Mobile phase A: $0.01 \mathrm{M}$ potassium dihydrogen orthophosphate was prepared and the $\mathrm{pH}$ was adjusted to 3.0 with orthophosphoric acid.

\section{Mobile phase B: Acetonitrile}

Gradient elution mode was used for the development of chromatogram. In 0 minute $\mathrm{A}$ : $\mathrm{B}$ is $85: 15$; for 15 to $18 \mathrm{~min}, \mathrm{~A}$ : $\mathrm{B}$ is 75:25; and for 18 to $21 \mathrm{~min} A: B$ is $85: 15$.

\section{Diluent}

The mixture of Water and Acetonitrile in the ratio of 50:50v/v was prepared and used as diluents.

\section{Impurities stock standard solutions}

Each 5 mg of EMP RC01 (Impurity A) and EMP RC05 (Impurity B). impurity standards were weighed accurately and transferred into individual each $10 \mathrm{ml}$ volumetric flasks. $5 \mathrm{ml}$ of diluents was added into each flasks and sonicated to dissolve the mixtures. Finally, the solution was made up to the volume with diluent and mixed well

\section{Diluted standard solution (Resolution solution)}

From the impurities standard stock solution, each $2 \mathrm{ml}$ of solution was transferred into $50 \mathrm{ml}$ volumetric flask and made up the volume up to mark with diluent.

\section{Sample preparation}

$10 \mathrm{mg}$ of Eprosartan has weighed accurately about into $10 \mathrm{ml}$ volumetric flasks. $5 \mathrm{ml}$ of diluent

was added to the flasks and sonicated to dissolve the material. Finally, the solution was made up to the volume with diluents.

All final solutions were filtered using microfiltration unit of $0.45 \mu \mathrm{m}$.

\section{Validation}

The proposed method was validated for the analysis of EM, EMP RC01 and EMP RC05 using following parameters. System-suitability studies are an intact part of method development and are practiced to ensure satisfactory performance of the chromatographic system. For five replicate injections of the drugs and impurities, Number of theoretical plates $(\mathrm{N})$ and tailing factor (T) were assessed. Linearity was established by plotting a graph between concentration versus peak area and the correlation coefficient was determined. A series of solutions of Eprosartan impurities with concentrations ranging from LOQ $\%$ to $200 \%$ of the target concentration $(0.5 \%)$ prepared and injected into the HPLC system. To obtain proportionality, the slope and intercept of the regression line and correlation coefficient were calculated statistically from the calibration curve of the EM and its impurities. To find out variations in the test methods precision was studied for EM and its impurities of spiked test preparation with Eprosartan impurities blend solution to get $0.5 \%$ of each impurity with respect to test concentration and analyzed as per test method when analysis carried out by Analyst to Analyst, System to System and Column to Column Variation (ruggedness). The mentioned solution was injected six times and the area was measured for all six injections in HPLC. The \% relative standard deviation (\%RSD) and \% content results were used for assessment of precision and ruggedness. The accuracy of the method was demonstrated by analyzing EM and its impurities of spiked test preparation with LOQ, $50 \%, 80 \%, 100 \%, 150 \%$ and $200 \%(0.025,12.5,20,25,40$ and 50 $\mu \mathrm{g} / \mathrm{ml}$ ) of target concentration (i.e., $0.5 \%$ of each impurity) of Eprosartan impurities. After injection, recovery values for individual drugs were estimated. Specificity is the ability of a method to differentiate the analyte(s) of interest from other components in the sample. Placebo was prepared as per the marketed product formulas of drugs. Placebo interference from excipients was studied. Robustness of the method was determined by varying flow rate, and filtration. Bench top stability $\left(25^{\circ} \mathrm{C}\right.$ and $\left.60 \% \mathrm{RH}\right)$ and Refrigerator $\left(8{ }^{\circ} \mathrm{C}\right.$ and $\left.55 \% \mathrm{RH}\right)$ stability were determined on the $1^{\text {st }}$ and $2^{\text {nd }}$ day. Forced degradation study was conducted to demonstrate the effective separation of degradants from EM. EM was exposed to the following stress conditions such as refluxed with $0.1 \mathrm{~N} \mathrm{HCl}$ solution for about $2 \mathrm{~h}$ at $60{ }^{\circ} \mathrm{C}$ (Acid). Refluxed with $0.1 \mathrm{~N} \mathrm{NaOH}$ solution for about $2 \mathrm{~h} 30 \mathrm{~min}$ at $60{ }^{\circ} \mathrm{C}$ (Base). Treated with $1 \%$ Hydrogen peroxide $\left(\mathrm{H}_{2} \mathrm{O}_{2}\right)$ for $2 \mathrm{~h}$ at $25^{\circ} \mathrm{C}$ (Peroxide). Refluxed with purified water for about $6 \mathrm{~h}$ at $60^{\circ} \mathrm{C}$. (Aqueous). Exposed to Sun-Light for about 1.2 Million. Lux. Hours. Exposed to UV-Light for about 200 Watts $/ \mathrm{m} 2$. Dry heat at $105^{\circ} \mathrm{C}$ for about $24 \mathrm{~h}$. Exposed to humidity at $25{ }^{\circ} \mathrm{C}, 90 \% \mathrm{RH}$ for about $7 \mathrm{~d}$ to induce degradation. Limit of detection and limit of quantitation were determined by signal to noise ratio. The precision of Eprosartan impurities at about Limit of 
Quantitation level was conducted. Six test preparations having impurities at the concentration level of about Limit of Quantitation in the presence of placebo were prepared and injected into HPLC system.

\section{RESULTS}

Gradient reverse-phase HPLC procedure was suggested as a suitable method for the analysis of EM and known impurities. Buffer and acetonitrile mixture in the proportion of above-mentioned proportion based on time at a flow rate of $0.8 \mathrm{ml} / \mathrm{min}$ was found to be a suitable mobile phase for complete and rapid separation of analytes. 7.76, 14.03 and $18.66 \mathrm{~min}$ were the retention times for EM, EMP RC01 and EMP RC05 respectively.

\section{System suitability parameters}

System suitability studies for the EM, EMP RC01 and EMP RC05 reported that the \% relative standard deviation values of five replicate injections of different solutions of EMP RC01 and EMP RC05 compare with EM were found to be 1.81 and 2.4. The theoretical plates for the EM, EMP RC01 and EMP RC05 were found to be 5758,6154 and 5199 respectively. The related data were presented in table 1 .

Table 1: System suitability studies data

\begin{tabular}{lllll}
\hline System suitability parameters & Observed value & Acceptance criteria \\
\cline { 2 - 4 } & $\begin{array}{l}\text { Eprosartan } \\
\text { mesylate }\end{array}$ & $\begin{array}{l}\text { Impurity A (EMP } \\
\text { RC01) }\end{array}$ & $\begin{array}{l}\text { Impurity B (EMP } \\
\text { RC05) }\end{array}$ & \\
\hline Percentage relative standard deviation & 0.1 & 0.6 & 0.1 & \% RSD should not be more than 2.0 \\
Theoretical plates & 5758 & 6154 & 5199 & Not less than 3500 \\
\hline
\end{tabular}

\section{Linearity}

A linear calibration curve was obtained over the concentration range from 0.025 to $50 \mu \mathrm{g} / \mathrm{ml}$ of spiked impurities into the test and impurities solution for quantitative application purpose. The correlation coefficient for EM, EMP RC01 and EMP RC05 were 0.9999, 0.9999 and 0.9997 respectively. The calibration curve of EM, EMP RC01 and EMP RC05 was present in fig. 3. The regression equation of
EM was found to be $y=39765 x+4764$ with a coefficient of correlation 0.9999. The regression equation of EMP RCO1 was found to be $y=58316 x-4377$ with a coefficient of correlation 0.9999 , the regression equation of EMP RCO5 was found to be $y=62627 x-25360$ with a coefficient of correlation 0.9997 where $\mathrm{x}$ is concentration and $\mathrm{y}$ is absorbance. The curve fittings of EM, EMP RCO1 and EMP RCO5 were found to be $99.99 \%, 99.99$ and $99.97 \%$ respectively. The related linearity data of EM, EMP RCO1 and EMP RCO5 was present in table 2.

Table 2: Linearity results

\begin{tabular}{|c|c|c|c|c|c|c|}
\hline \multirow[t]{2}{*}{ Spiked samples } & \multicolumn{2}{|c|}{ Eprosartan Mesylate } & \multicolumn{2}{|c|}{ Impurity A (EMP RC01) } & \multicolumn{2}{|c|}{ Impurity B (EMP RC05) } \\
\hline & Concentration & Response & Concentration & Response & Concentration & Response \\
\hline & 0.02 & 823 & 0.03 & 1812 & 0.03 & 1916 \\
\hline & 12.4 & 504749 & 12.422 & 741508 & 12.502 & 753741 \\
\hline & 19.84 & 794211 & 19.876 & 1167607 & 20.004 & 1222085 \\
\hline & 24.8 & 992360 & 24.845 & 1441049 & 25.005 & 1515836 \\
\hline & 37.199 & 1478074 & 37.267 & 2171077 & 37.507 & 2295992 \\
\hline & 49.599 & 1978813 & 49.69 & 2908244 & 50.01 & 3142757 \\
\hline Slope & 39765 & & 58316 & & 62627 & \\
\hline intercept & 4764 & & -4377 & & -25360 & \\
\hline Correlation coefficient & 0.9999 & & 0.9999 & & 0.9997 & \\
\hline
\end{tabular}

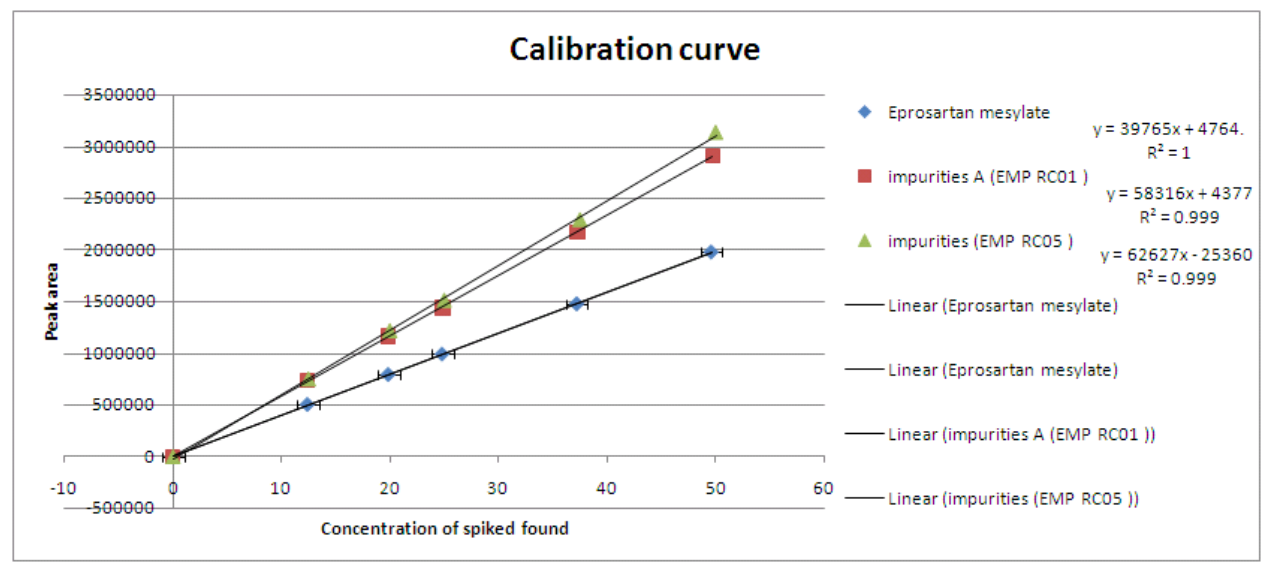

Fig. 3: Calibration curve of eprosartan mesylate and its impurities

\section{Precision}

The drugs got eluted giving single symmetrical peaks, well removed from the solvent front. The \% relative standard deviation (\%RSD) of the peak areas for five injections of the standard solution of EM, EMP RC01 and EMP RC05 was used for determination of the precision of the HPLC system. \%RSD for the EM, EMP RC01 and EMP RC05 were found to be $1.3 \%, 0.9 \%$ and $1.2 \%$ respectively for method precison and $0.1 \%, 0.1 \%$ and $0.1 \%$ respectively for system precision. The $\% \mathrm{RSD}$ of drugs and impurities under this method was not more than 2 .

\section{Accuracy studies}

Recovery studies were carried out by analyzing mixtures of spikied test preparation with LOQ, $50 \%, 80 \%, 100 \%, 150 \%$ and $200 \%$ of target concentration (i.e., $0.5 \%$ of each impurity) of Eprosartan 
impurities. The recoveries of EM, EMP RC01 and EMP RC05 were evaluated. The mean percentage recoveries for LOQ, $50 \%, 80 \%$, $100 \%, 150 \%$ and $200 \%$ accuracy were found to be $101.5 \% \pm 1.5$, $107 \% \pm 1.6,104.6 \% \pm 0.4,102.8 \% \pm 0.4,101.7 \% \pm 0.3$ and $101.3 \% \pm 0.2$ respectively for EM; $103.9 \% \pm 1.2,96 \% \pm 1.4,96.2 \% \pm 0.7,97.5 \% \pm 0.2$, $98.1 \% \pm 0.3$ and $97.8 \% \pm 0.2$ respectively for the EMP RC01; and $98.6 \% \pm 1.1, \quad 103 \% \pm 2.9, \quad 99 \% \pm 2.0, \quad 96.8 \% \pm 0.8, \quad 96.2 \% \pm 1.3$ and $101.7 \% \pm 0.6$ respectively for the EMP RC05. The results of percentage recovery data were within the limit.

\section{Limit of detection and limit of quantitation}

Limit of Detection and Limit of Quantitation were established based on the signal to noise ratio. Limit of detection by signal to noise ratio of EM, EMP RC01 and EMP RC05 were found to be 3.5, 3.6 and 3.0 respectively. Limit of quantitation by signal to noise ratio of EM, EMP RC01 and EMP RC05 were found to be be 9.8, 10.1 and 9.3 respectively. \% recovery of LOQ level of EM, EMP RC01 and EMP RC05 were found to be $102.8 \% \pm 2.1,103.9 \% \pm 1.31$, and $99.5 \% \pm 1.53$ respectively. \%RSD value of LOQ level of EM, EMP RC01 and EMP RC05 were found to be 2.1, 1.3 and 1.5 respectively.

\section{Ruggedness}

Ruggedness for EM, EMP RC01 and EMP RC05 determined by varying analysts, system and column carrying out the procedure. Totally 2 analysts, systems and columns carried out the procedure and the results were within the limits.

\section{Robustness}

Robustness of the method was determined by varying flow rate and filter. The optimized method flow rate was $0.8 \mathrm{ml} / \mathrm{min}$ and robustness was varied to $0.7 \mathrm{ml} / \mathrm{min}$ and $0.9 \mathrm{ml} / \mathrm{min}$. The optimized filtration is $0.45 \mu \mathrm{m}$ PVDF and it was varied to unfiltered and 0.45 $\mu \mathrm{m}$ Nylon. The variation in flow rate and filter membrane for filtration was not shown any deviation from the true value and $\%$ RSD of all variations were within the limit.

\section{Stability studies}

Stability studies (Refrigerator stability and Benchtop stability) have reported the percentage deviation from the true value within the limit for EM, EMP RC01 and EMP RC05. Stability data were presented in table 3.

\section{Forced degradation studies}

Forced degradation studies reports shown little deviation in EM Percentage deviation of forced degradation studies was mentioned in table 4.

Table 3: Stability and robustness data

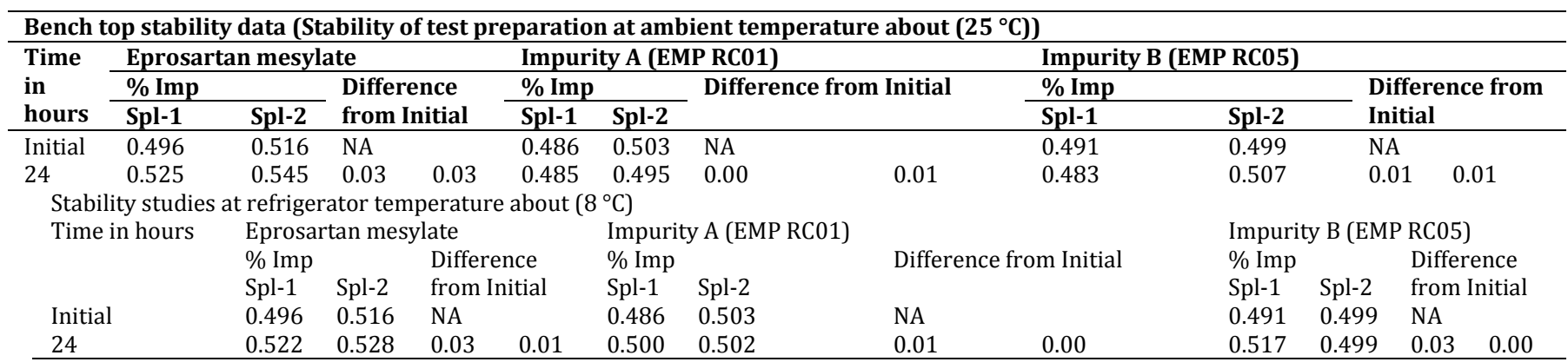

Table 4: Forced degradation data

\begin{tabular}{lll}
\hline Eprosartan mesylate & Area & \% Degradation \\
\hline Unstressed & 42630 & 0 \\
Acid stressed & 41613 & 2.39 \\
Base stressed & 41160 & 3.45 \\
H202 stressed & 40185 & 5.74 \\
Thermal stressed & 41232 & 3.28 \\
Humidity & 41025 & 3.76 \\
\hline
\end{tabular}

\section{DISCUSSION}

The developed method can be used for routine analysis because the linearity found in EM, EMP RC01 and EMP RC05 is nearing 1 that is $0.9999,0.9999$ and 0.9997 respectively which shows the good regression for linearity. Maximum recovery is obtained by this developed method and the mean percentage recovery for each component is nearing $100 \%$. Therefore this method can be used for the routine analysis and one most important reason is that the developed method does not involve the use of expensive reagents. The spectrophotometric assay methods employed in our study indicated less interference from excipients used in the formulation by the percent recoveries values. Most of the existing methods consumed expensive reagents for individual drug analysis. But the method we developed involves chemicals like acetonitrile and buffer, which are easily available. Also, our proposed method requires less time for the determination of known impurities of EM simultaneously compared to other methods.

\section{CONCLUSION}

The developed method is uncomplicated, accurate, sensitive and precise for the determination of related substances in the
Eprosartan Mesylate. The satisfying \% recoveries and low \% RSD Values confirmed the suitability of the developed method for the usual analysis of Eprosartan mesylate in pharmaceuticals.

\section{ACKNOWLEDGEMENT}

The authors would like to thank Department of Chemistry, Institute of science, Gitam University, Visakhapatnam for providing necessary facilities. The authors are also grateful to Fortunnee labs, Kakinada for providing gift sample of eprosartan mesylate drug and its known impurities.

\section{CONFLICT OF INTERESTS}

Declare none

\section{REFERENCES}

1. http://www.drugbank.ca/drugs/DB00876. [Last accessed on 01 Jan 2016].

2. http://www.tlcstandards.com/ProdDetail.aspx?ID=E1510andname=EPROSARTAN. [Last accessed on 01 Jan 2016].

3. www.usp.org/sites/default/files/usp_pdf/EN/USPNF/./m587 5.pdf. [Last accessed on 01 Jan 2016]. 
4. http://tlcpharma.com/productdetails.php?subcatid=179. [Last accessed on 01 Jan 2016].

5. Nandakumar K, Santhi DV, Jothieswari D, Subathrai R Vetrichelvan T. Development and validation of a UV spectrophotometric method for the simultaneous estimation of eprosartan mesylate and hydrochlorothiazide in bulk and formulations. Indian J Pharm Sci 2011;73:569-72.

6. K Veerreddy, Teja kumar P, Sunil K Dandeti, Bolli Sandeep. Simultaneous UV spectroscopic analysis of eprosartan mesylate and hydrochlorothiazide tablets by absorption ratio method. J Pharm Res 2012;5:4371-4.

7. Anandakumar K, Vijaya Santhi D, Jayamariappan M. Development and validation of eprosartan mesylate and hydrochlorothiazide in pure and in fixed-dose combination by UV spectrophotometry. Int J Pharm Indian Res 2011;1:22-7.

8. Rewar S, Bansal BK, Singh CJ, Sharma AK. Approach for quantitative estimation of eprosartan mesylate by UV spectrophotometer. Int J Res Dev Pharm Life Sci 2014;3:1300-3.

9. Abdul Ahad, Abdullah Mohammed Al-Mohizea, Abdulmohsen Abdullah Al-Saleh, Abdullah Sulaman Alwabel, Abdulaziz Jaber Aqel, Khalid Mahdi Al-Qahtani, et al. Validation of a rapid and sensitive HPLC-UV method for the quantification of eprosartan mesylate in bulk drug, teventen TM and ultra deformable lipidbased vesicular system. Curr Pharm Anal 2016;12:1-6.
10. Sitaram Cheekatla, Ravichandrababu Rupakula, Bommineni Narasimha Reddy, Musty Sharada. Determination and characterization of process impurities for Eprosartan Mesylate. J Pharm Res 2013;6:504-9.

11. Patel HU, Suhagia BN, Patel CN. Simultaneous analysis of eprosartan and hydrochlorothiazide in tablets by highperformance liquid chromatography. Pharm Methods 2011;2:143-7.

12. V Kiran Kumar, N Appala Raju, Jvln Seshagiri Rao, T Satyanarayana. The estimation of eprosartan mesylate in pharmaceutical dosage forms by RP-HPLC Orient. J Chem 2009;25:711-4.

13. Vineeta Khanvilkar. HPTLC method for determination of eprosartan mesylate in human plasma. Indo Am J Pharm Res 2013:3;10.

14. Ravi Piyushkumar Shah, Archana Sahu, Saranjit Singh Identification and characterization of geometrical isomeric photodegradation product of eprosartan using LC-MS and LC-NMR. Eur J Chem 2011;2:152-7.

\section{How to cite this article}

- $\quad$ OSS Chandana, D Sathis Kumar, R Ravichandra Babu. Method development and validation of eprosartan mesylate and its impurities using reverse phase high-performance liquid chromatography. Int J Curr Pharm Res 2016;8(4):49-53. 